\title{
SAÚDE E GESTÃO NA AVIAÇÃO: A EXPERIÊNCIA DE PILOTOS E CONTROLADORES DE TRÁFEGO AÉREO
}

\author{
Alice Itani \\ Centro Universitário Senac, São Paulo, Brasil
}

\begin{abstract}
RESUMO: A aviação comercial é um ramo de atividade que apresenta um alto crescimento nas últimas duas décadas. Esse crescimento tem um impacto sobre a saúde do trabalhador do transporte aéreo, regulada por normas da aviação civil, sob responsabilidade do Estado. As políticas de gestão da saúde podem ser analisadas por meio do estudo realizado com pilotos e controladores de tráfego aéreo no período entre 1992 e 2004. Partiu-se da hipótese que a saúde é um atributo principal de qualificação, mas as práticas de gestão da saúde são contraditórias às exigências para o exercício das funções.
\end{abstract}

PALAVRAS-CHAVE: saúde; aviação; pilotos; controladores de tráfego aéreo; condições de trabalho

\section{HEALTH AND MANAGEMENT IN AVIATION. THE EXPERIENCE OF AIR FLIGHT PILOTS AND AIR TRAFIC CONTROLLERS}

\begin{abstract}
The civil aviation has presented a high growth in the past three decades which has an actual effect on the aviation worker's health. The health of the aviation worker is ruled by civil aviation laws under the responsibility of the State. The health policies can be analysed by the data from pilots and air traffic controllers study undertaken during the period of 1992 and 2004. The hypothesis is that health is an important attribute of the qualification among pilots and air traffic controllers but the health management policies are contradictory when compared to the job demands.
\end{abstract}

KEYWORDS: occupational health; aviation; air flight pilots; air traffic controllers; working contidions

\section{Introdução}

O notável crescimento do transporte aéreo no Brasil nas últimas décadas mostra a importância desse setor para a economia tanto no transporte de passageiros quanto no transporte de mercadorias. Do lado desse crescimento, algumas mudanças se desenvolvem no interior do setor e que fazem parte de formas de organização e gestão.

Como a gestão da saúde é vivida pelos(as) trabalhadores(as) da aviação? Dentre as questões do estudo sobre as condições de trabalho de trabalhadores (as) da aviação, buscou-se compreender como as políticas de gestão da saúde afetam aqueles que estão mais diretamente envolvidos pela produção do transporte aéreo, quais sejam, os que estão nos postos de piloto e controlador de tráfego aéreo. Uma das hipóteses do estudo é que apresentar boa saúde se constitui como um atributo de qualificação, mas as políticas de gestão da saúde são contraditórias às exigências de qualidade de saúde que os(as) trabalhadores(as) da aviação precisam apresentar para exercer essas funções.

O presente texto tem por finalidade apresentar alguns aspectos do estudo sobre as condições de trabalho de trabalhadores da aviação, buscando contribuir para estudo de gestão da saúde nas organizações. Resulta de um estudo realizado com os(as) trabalhadores(as) da aviação em São Paulo e Rio de Janeiro entre 1992 e 2004.

\section{A aviação civil brasileira}

A aviação comercial possui algumas características que são atribuídas às suas origens, militar e de controle do Estado. A aviação se desenvolve de maneira marcante no período das duas Grandes Guerras mundiais do século XX, no processo de crise das economias ocidentais, e também decorrente da saturação do sistema técnico. Entre a Primeira Grande Guerra Mundial e a queda da Bolsa de Wall Street, a técnica, até então implementada, não foi capaz de responder nem em quantidade nem em custo o crescimento, quando a produção passa de 32 milhões de toneladas de aço em 1913, para 57 milhões em 1929 (Gille, 1978). A aviação aparece no cenário da economia ocidental com as Grandes Guerras Mundiais pelos motivos que as provocaram como pelos desafios postos nessas guerras. $\mathrm{O}$ avião, já presente na Primeira Grande Guerra, associa duas variáveis importantes, o custo e a rapidez. Em 1919 os 
serviços de aviação civil podem ser verificados em trechos pontuais e pequenos equipamentos, mas realizando assim mesmo $5.150 \mathrm{~km}$. Os voos fazem, por exemplo, trechos como Paris-Londres, com 11 passageiros ou Paris-Bruxelas com cinco passageiros. As empresas são pequenas, como é o caso de uma companhia alemã formada para fazer Berlim-Hamburgo e Berlim-Leipzig ou ainda, uma companhia inglesa para atravessar o Mar da Mancha (Gille, 1978).

Mais que em outros períodos precedentes, as soluções técnicas são buscadas, associando novas técnicas às possibilidades da ciência. Os problemas de limitação de velocidade e o desempenho do avião são superados com a aplicação do turbo-propulsor e turboreator, substituindo o motor clássico a pistão. $\mathrm{O}$ aumento da velocidade passa a ser notável, aumentando, já em 1920, a velocidade dos voos de $265 \mathrm{~km}$ por hora para $305 \mathrm{~km}$ por hora. Quatro anos depois essa velocidade já chega a $448 \mathrm{~km}$ por hora. $\mathrm{O}$ desafio das grandes distâncias começa a ser rompido com a travessia do Oceano Atlântico em 1927. Em 1929 já são realizados $202.500 \mathrm{~km}$ por avião. Em 1939 a Pan Am faz a primeira travessia comercial entre Marselha e Washington com um hidroavião gigante, o Boeing 314 Dixie Clipper transportando 22 passageiros (Gille, 1978).

As mudanças se desenvolvem também como resultado da aplicação de pesquisas realizadas com novos materiais, desde o final do século 19. As novas soluções técnicas e procedimentos são testados e implementados na aviação. Nas duas Grandes Guerras a revolução científica coloca em competição dois sistemas políticos mundiais, o industrial e o militar. O tempo para a travessia do Atlântico Norte, por exemplo, reduz de 33 horas para 23 horas com o equipamento DC-4 com 44 passageiros já em 1946. Em 1960, o quadrirreator Boeing $707 \mathrm{fez}$ essa travessia em sete horas e meia com 144 passageiros e, assim, em 1963, quase três milhões de passageiros fazem essa travessia. Os anos 70 é marcado pelo auge da aviação. É o momento do lançamento do Boeing 747, multiplicando por 16 a produtividade lugares $/ \mathrm{km}$ por hora de voo, transportando 357 passageiros num voo, que contribui para se transportar mais de nove milhões de passageiros no ano. E também o Concorde, que é lançado em 1973 para fazer o trecho Paris-Washington em três horas e meia.

O transporte aéreo é privilegiado, sobretudo, para o transporte de mercadorias para grandes distâncias, diminuindo as vantagens das médias distâncias, acelerando o processo de produção em massa. Além das alternativas do transporte ferroviário e o marítimo centra-se agora também sobre o transporte aéreo, possibilitando a invasão de novos mercados em outros continentes. Para se ter noção da dimensão dessa circulação aérea, podese verificar, por exemplo, que no inverno de 1948, 150 mil toneladas de mercadorias foram transportadas dos EUA para Berlim Ocidental. Em pouco mais de vinte anos, entre 1945 e 1967, o transporte aéreo quadruplicou a quantidade de mercadorias transportadas e, entre 1950 e 1970, a quantidade de passageiros multiplicou por $10 \mathrm{e}$ o número de $\mathrm{km}$ multiplicou por 15. Em 1972, o Boeing 747 já transportava 100 toneladas de mercadorias entre Frankfurt e Nova York (Gille, 1978).

O crescimento da aviação civil no mundo apresenta-se como parte de um processo em transformação do sistema produtivo, dependente da produção industrial em grande escala, do avanço da grande indústria no deslocamento de mercadorias para diferentes mercados e espaços de produção. O aumento da velocidade possibilitou a aceleração na circulação de mercadorias e, decorrente disso, utilizando-se dessas possibilidades e, associado aos dos diversos sistemas de telecomunicações, houve também a quebra de fronteiras de territórios.

As mudanças nesse setor estão interligadas notadamente à forte intervenção do Estado. $\mathrm{O}$ transporte aéreo é, de fato, o lugar onde se exerce o poder de Estado. Primeiro, porque o espaço aéreo é controlado pelo Estado. Segundo, porque permite realizar a unidade do território reduzindo as distâncias entre as fronteiras. Terceiro, porque permite ao Estado interligar os centros econômicos e de poder a outras regiões. Quarto, porque o transporte foi criado como um serviço público pelo direito do cidadão ao transporte, mesmo se gerido como negócio privado. A atividade da aviação civil é fortemente regulamentada pelo Estado, tanto no processo de produção como nas relações de trabalho, pela estruturação da produção e do mercado de trabalho, desde a formação até o exercício profissional e a forma como essas ocupações são estruturadas e controladas nas organizações.

Entretanto, esse lugar privilegiado de intervenção estatal aéreo desenvolve um setor com alto custo reafirmando a justificativa do monopólio por parte do Estado (Barca, 1993). O crescimento da aviação civil se insere como parte de um processo em transformação do sistema produtivo, do avanço da grande indústria no deslocamento de mercadorias para diferentes mercados e espaços de produção. As mudanças no sistema produtivo desde os anos oitenta implicaram também num processo de desregulamentação do setor (Dempsey, 1993). Passados os trinta gloriosos anos do pós-guerra, altera-se profundamente a relação entre o setor e o Estado. Novas formas de mercado se estruturam como também novas formas de concorrência, sobretudo novas relações de trabalho. Esse processo de mudanças não rompeu, no entanto, com as contradições presentes, como a importância estratégica da aviação como presença hegemônica do poder de centros econômicos sobre regiões periféricas. Também não se pode negar a 
importância do desenvolvimento do setor para a aplicação e difusão de novas tecnologias de informação associadas a sistemas eletrônicos e de comunicação e, por consequência, da indústria aeronáutica. A contradição maior incide sobre o alto custo desse transporte e a não-aplicabilidade da economia de escala (Barca, 1993), mesmo se sua produção passa a se desenvolver em redes, entre as companhias aéreas mundiais.

A organização desse setor está relacionada com o controle estatal do transporte aéreo, sobretudo pelo lugar por onde se exerce o poder de Estado. Primeiro, porque o espaço aéreo é de domínio do Estado. Segundo, porque permite realizar a unidade do território reduzindo as distâncias entre as fronteiras. Terceiro, porque permite ao Estado interligar os centros econômicos e de poder a outras regiões. Quarto, porque o transporte foi criado como um serviço público pelo direito do cidadão ao transporte, mesmo se gerido como negócio privado. A atividade da aviação civil é fortemente regulamentada pelo Estado, tanto no processo de produção como nas relações de trabalho, pela estruturação da produção e do mercado de trabalho, desde a formação até o exercício profissional e a forma como essas ocupações são estruturadas e controladas nas organizações.

No caso brasileiro, o transporte aéreo tem papel fundamental dada as grandes distâncias do território, e que passam a ser transpostas pela difusão da aviação. Os passageiros são deslocados pelo território, em maior rapidez, e as mercadorias são transportadas em maior quantidade, pelas possibilidades de utilização da capacidade dos equipamentos.

O crescimento do setor se insere também dentro de grandes mudanças ao longo das últimas três décadas. Podemos destacar dois pontos importantes que mostram isso. Um primeiro, do aumento da velocidade. A aceleração na circulação de mercadorias e deslocamento de passageiros de um ponto a outro utiliza-se do desenvolvimento de equipamentos de transporte aéreo e novos materiais, bem como das possibilidades dos diversos sistemas de telecomunicações e informação. O maior impulso foi com o desenvolvimento e difusão dos jatos nos anos 70. No Brasil, pode-se verificar que as melhorias nos equipamentos possibilitaram também um aumento de $30 \%$ na velocidade média dos equipamentos, na década de noventa. A frota brasileira da aviação civil, por exemplo, mudou em menos de vinte anos. Se no início da década de oitenta, a frota era de turboélice, em 1986 contava ainda com 10\% dela, e nos anos noventa ela é toda composta por jatos, conforme dados do Anuário Estatístico do DAC. O jato médio é difundido no tráfego regional e o táxi aéreo é dominado pelos chamados jatinhos. A velocidade média dos equipamentos passou de 680 para $723 \mathrm{~km}$ por hora no tráfego nacional e de 320 para 405 no regional, con- forme dados do Anuário Estatístico do DAC. Os voos passam também a ter autonomia de 12 a 15 horas.

Um segundo ponto é a difusão do uso do avião como meio de deslocamento, sobretudo para grandes distâncias. Isso pode ser verificado tanto pelo aumento de passageiros quanto pela difusão de equipamentos de maior capacidade. No início dos anos noventa, verificase que a quantidade de passageiros dobra em menos de quatro anos. Há a utilização de novos modelos de aeronaves com maior capacidade e com oferta de maior quantidade de assentos em cada voo. Isso possibilita também a redução do custo da passagem por passageiro, tanto nas rotas nacionais quanto internacionais. As aeronaves McDougall, o modelo MD-11 chegavam a transportar 300 passageiros, e 400 passageiros em média com o equipamento da Boeing, o modelo B 747-400. No transporte regional, foi difundido o equipamento de médio porte, utilizando-se tanto o equipamento da Boeing modelo B 737 como o equipamento da Fokker, o Fokker 100 que transporta 100 passageiros em média.

$\mathrm{O}$ aumento da velocidade e da capacidade dos equipamentos e da difusão do transporte aéreo possibilitou o crescimento da aviação civil que pode ser verificado pelo aumento do tráfego aéreo. Se tomarmos o caso regional de São Paulo verifica-se que o tráfego dobrou em seis anos, entre 1992 e 1998. Os três aeroportos que se situam dentro da cidade de São Paulo foram os que apresentaram maior crescimento. O Aeroporto Internacional de Guarulhos apresentou um aumento de $160 \%$, o Aeroporto Internacional de Congonhas teve um aumento de $236 \%$ e o Aeroporto de Campo de Marte teve o maior crescimento: $286 \%$, conforme dados do Serviço Regional de Proteção ao Voo - SRPV. Esse Serviço Regional de São Paulo respondia por mais de 1.800 voos por dia, no início do ano 2.000. A indústria do transporte aéreo deslocava no final dos anos noventa do século XX mais de 50 milhões de passageiros por ano no espaço aéreo brasileiro. Somente os três aeroportos de São Paulo respondiam por 25 milhões de passageiros no início do ano 2000, conforme dados do Departamento de Aviação Civil - DAC. As três grandes empresas de transporte aéreo nacional foram responsáveis pelo transporte de mais de quatro bilhões de toneladas de mercadorias $/ \mathrm{km} /$ ano e mais de 26 milhões de passageiros embarcados no ano de 1998. O aumento foi mais marcante entre as linhas regionais e táxis. O conjunto da indústria do transporte aéreo registrou um crescimento de $600 \%$, passando de um milhão e meio de passageiros, no início da década, para nove milhões, sete anos depois, e, desses, dois milhões somente na linha Rio-São Paulo.

Esse crescimento se desenvolve dentro de um processo de desregulamentação do transporte aéreo, que se iniciou no final dos anos 70, rompendo com o mono- 
pólio dos espaços territoriais pelas empresas nacionais (Dempsey, 1993). Mas essas mudanças se desenvolvem também na organização e gestão do transporte aéreo em nível mundial e, no contexto dessas mudanças, os trabalhadores da aviação enfrentam múltiplos desafios. Um primeiro, de adaptação a diferentes níveis de velocidade. $\mathrm{O}$ aumento da velocidade das aeronaves e, sobretudo, dos sistemas, implicaram mudança no ritmo da atividade. A aceleração dos sistemas e equipamentos requer rapidez nas ações e operações, afetando os processos decisórios, fazendo parte intrínseca do processo de trabalho. Para o controle de tráfego são também implantados novos sistemas de informação nos anos setenta do século XX.

As tecnologias introduzidas na aviação compreenderam mudanças dos sistemas de aeronaves, os sistemas de aeronavegação bem como os sistemas de gestão de reserva e os sistemas de gestão da circulação aérea. O ritmo da velocidade passa a fazer parte da gestão do transporte aéreo, associando também práticas de maior tempo de uso das aeronaves e redução de tempo de manutenção. Essa utilização, cada vez mais intensa, dos equipamentos, com a redução no tempo de parada das aeronaves em terra e no tempo de manutenção dos sistemas e equipamentos, implicou também mais tempo de trabalho de um conjunto de trabalhadores envolvidos.

No caso brasileiro, essas mudanças tecnológicas puderam ser notadas também na gestão do tráfego aéreo, sobretudo nos anos setenta e oitenta do século $\mathrm{XX}$. Os controladores comandam o tráfego de todos os voos que circulam no espaço aéreo, notadamente nos grandes centros, apoiado sobre informações de um sistema denominado Sisdacta, Sistema Integrado de Defesa Aérea e Controle de Tráfego Aéreo, com capacidade de detecção e captação de dados via radar, de processamento e de transmissão de dados apoiados sobre um sistema de apoio à visualização associados ao programa horário de voos.

No entanto, essas mudanças não foram acompanhadas por um processo de manutenção e organização do transporte bem como de sistemas de gestão do tráfego aéreo. O processo de gestão do transporte aéreo se desenvolve em ritmo distinto dos sistemas e equipamentos. Mesmo como o crescimento do setor, os investimentos foram restritos. Muitos dos equipamentos apresentavam problemas de funcionamento nos anos noventa do século XX bem como se verificou falta de pessoal e de treinamento, sobretudo no tráfego aéreo.

Outro desafio enfrentado foi o das diferentes mudanças com a desregulamentação na aviação. Dentro desse processo imposto pelas companhias internacionais são alteradas também as práticas de gestão. Novas políticas são impostas dentro de um processo de flexi- bilização como sinônimo de rapidez e modernidade. As possibilidades de circulação e de rapidez da informação tomam conta dos processos produtivos impulsionados por novos padrões de flexibilização, seja na produção, seja nas relações de trabalho.

\section{Condições de trabalho e a saúde}

A experiência no trabalho na aviação civil é marcada pelo risco. A experiência de pilotos e controladores de tráfego aéreo é com uma atividade que requer precisão na decisão. De outro lado, a atividade deve ser realizada com rapidez. $\mathrm{O}$ trabalho na aviação foi analisado sobretudo em relação ao trabalho em turnos e às condições de biorritmos de pilotos, os turnos rodiziantes contrários aos ritmos circadianos dos organismos (Fischer, 1991). Também as condições de trabalho de pilotos de uma das companhias são analisadas por meio das jornadas e salários (Ferreira, 1992). Ainda, os aspectos ergonômicos da sala de controle de tráfego aéreo do Rio de Janeiro dificultam a realização do trabalho (Vidal \& Moreira, 1999).

Compreende-se que as condições de trabalho são a objetivação de formas de dominação mais direta, tais como elas se desenvolvem nas relações de trabalho (Castel, 1993). Elas revelam a organização do trabalho tal como está estruturado nos espaços de trabalho e afetam a qualidade de vida e, por conseguinte, a saúde do trabalhador (Dejours, 1985). As condições vividas pelo(a) trabalhador(a) são decorrentes de práticas de gestão tais como elas se desenvolvem no cotidiano das relações de trabalho. O corpo do(a) trabalhador(a) pode revelar essas práticas. São os danos e os riscos da vivência nessas condições dadas dos locais e espaços de trabalho. O corpo revela, também, a atenção e os cuidados à saúde no cotidiano dos locais de trabalho. Nesse sentido, compreende-se que a saúde pode ser verificada pela inscrição da ordem social no corpo dos indivíduos (Boltanski, 1984). Isto é, a saúde pode ser analisada pela experiência de trabalho, e, por conseguinte, pelas perdas e pelas doenças que são produzidas pelos organismos no espaço de trabalho. Ela revela as práticas de uso do trabalho ou, mesmo, como uma ação do poder das instituições (Fassin, 1996) na gestão dos espaços de trabalho (Dejours, 1985).

Compreende-se que a saúde resulta de um processo de produção social que se desenvolve nos espaços sociais, dependente de um conjunto de condições de vida produzidas coletivamente. A saúde do(a) trabalhador(a), como um bem individual, resulta de uma produção coletiva, de uma qualidade de vida individual e coletiva, onde se incluem as condições de trabalho. Essa produção requer cuidados e atenção permanentes, estando o organismo em constante movimento, num processo 
dinâmico de busca de equilíbrio por seu mecanismo biológico de regulação (Berlinguer, 2005).

As políticas de saúde, desse modo, podem ser analisadas pelas ações e práticas, tanto das instituições públicas responsáveis pela atenção, cuidado e preservação da saúde, como das empresas em relação a seus trabalhadores, e das instituições privadas de saúde. Nesse entendimento, estiveram em foco desde os aspectos físicos ambientais até organizacionais, passando pelas condições pelas quais essas condições são vividas por essa categoria de trabalhadores em seus cotidianos de vida e trabalho. De mesma maneira, buscou-se levantar a noção de saúde tal como ela é compreendida e gerida nesses espaços de trabalho e como ela afeta essa categoria de trabalhadores.

Para o estudo das condições de trabalho na aviação foi privilegiada a experiência dos trabalhadores nas relações de trabalho. Por conseguinte, foram consideradas as relações que se estabelecem nesse ramo de atividade e espaço específico.

Para a análise da qualificação dos pilotos e controladores de tráfego aéreo foram consideradas as políticas de gestão referentes às exigências de qualificação. Dentre as exigências de qualificação do trabalhador estão sempre os aspectos de nível de escolaridade ou formação profissional. Há estudos que levam em conta até mesmo os anos de estudo, como o caso de Lavorel (1987). Compreende-se qualificação como um conjunto de atributos do trabalhador, individual e inalienável, que integra sua capacidade de trabalho. É o saber do trabalhador, conhecimentos e habilidades. No caso da aviação, há outras exigências e que fazem parte dos procedimentos da aviação civil.

Nesse entendimento foi observada e apreendida a vivência do trabalhador no cotidiano do processo de trabalho, composta por observação do desenvolvimento do processo nos ambientes de trabalho e depoimentos, fazendo emergir a compreensão do trabalhador sobre seu trabalho, sobre o processo em que se insere. Trata-se de uma experiência compartilhada que se constrói pelas situações cotidianas vividas e que são também seus espaços de vida e trabalho. A experiência foi apreendida, desdobrada em dois momentos. Um primeiro, apoiado sobre a experiência que os controladores de tráfego aéreo e os pilotos vivem diante dos sistemas e equipamentos na realização do trabalho no cotidiano. Um segundo, sobre a experiência com o conflito das relações no embate cotidiano com as normas, com as chefias, com as controvérsias entre responsabilidades e autoridade.

Para tanto, foi realizado um estudo com método investigativo composto por quatro etapas: levantamento e revisão da literatura; levantamento de dados, por meio de documentação, normas, procedimentos, rotinas; observação de longa duração, durante mais de seis meses, acompanhando o desenvolvimento do processo do trabalho, bem como das normas, rotinas e procedimentos, por meio das práticas de políticas de gestão com diálogos para apreender o processo cotidiano, tal como é compreendido pelos que executam; e coletas de depoimentos, dentro e fora dos locais de trabalho para apreensão da compreensão sobre o processo de trabalho e saúde. A observação foi realizada em dias e horários alternados, cobrindo horários de pico e vale, em diferentes dias da semana.

Assim, foi efetuado um levantamento de sete itens, a saber:

1. Levantamento dos requisitos e exigências aos que se candidatam a postos de controlador de tráfego aéreo e piloto, de escolarização, de conhecimentos, de habilidades, no processo de seleção e de contratação;

2. Levantamento das aptidões físicas requeridas, pelos procedimentos dos exames e testes médicos, laboratoriais e psicológicos efetuados no momento da seleção e da contratação;

3. Levantamento das exigências de aptidões psicológicas e mentais, pelos testes e exames periódicos obrigatórios e entrevistas;

4. Levantamento e observação das condições das salas e locais de trabalho em que vivem esses profissionais;

5. Acompanhamento das formas de cuidado e atenção praticadas no cotidiano de trabalho desses profissionais, como atividades, cursos, regulação de pausas, orientação, normas e atividades desenvolvidas;

6. Entrevistas e depoimentos sobre as condições vividas por essa categoria de trabalhadores, desde horários de trabalho, jornadas, ritmos e turnos, salários, convênios e assistência médicohospitalar;

7. Levantamento dos procedimentos de acompanhamento de condições de saúde, das condições em que realizam tais acompanhamentos e das instituições que cuidam e acompanham a saúde desses(as) trabalhadores(as).

Foram seguidos os procedimentos do Código de Ética. O estudo foi realizado com autorização de acesso aos locais de estudo pelo Comando da Aeronáutica e pelos responsáveis pela coordenação de operação das empresas de aviação. O estudo foi realizado por solicitação dos trabalhadores da aviação. A cada depoimento foi explicado finalidade do estudo, beneficência, assegurando anonimato a cada um. Foi encaminhado o relatório do estudo aos solicitantes bem como ao SRPV-SP e RJ. 


\section{A saúde como qualificação}

Dentre os resultados levantados, podemos destacar três aspectos principais. Um primeiro, sobre as exigências de qualificação. Um segundo, sobre as formas pelas quais se realiza o controle dessas exigências. Um terceiro, as condições que os(as) trabalhadores(as) possuem no cotidiano do trabalho para atender tais exigências.

Os dados levantados mostraram que:

2.1. Os requisitos para os(as) candidatos(as) aos postos de controlador de tráfego aéreo e de piloto são, em princípio, o de escolaridade, com o certificado de segundo grau completo, ou o colegial completo, qual seja entre 11 a 12 anos de estudo. Mas, para o posto de piloto é necessário apresentar também o certificado de habilitação profissional, de piloto comercial, atribuído oficialmente por um órgão da Aeronáutica;

2.2. As exigências são também de conhecimentos técnicos, e para isso precisam passar obrigatoriamente por uma bateria de testes e exames de conhecimentos, gerais e específicos. Os que se candidatam aos postos de controlador de tráfego aéreo passam por um concurso público nacional de provas realizado pela Aeronáutica;

2.3. Os requisitos para se candidatar aos postos de piloto e de controlador de tráfego aéreo são também físicos e psicológicos. Os candidatos são submetidos a uma bateria de testes físicos, de exames laboratoriais e avaliação médica em diferentes especialidades. São exames, desde o radiológico pulmonar, até os sanguíneos e dermatológicos, passando pelos oftalmológicos, cardiológicos e parasitológicos. Também é obrigatório passar pelos exames psicotécnicos e entrevistas com psiquiatras e psicólogos. Esses exames são realizados nos hospitais da Aeronáutica.

2.4. Para o exercício da atividade de piloto, é obrigatória também apresentação da habilitação de piloto privado e comercial. Para a obtenção dessa habilitação, há uma bateria de testes e exames de saúde. Além disso, passa por testes e exames de habilidade em manejar equipamentos. E, ainda, exames técnicos e teóricos.

2.5. Para a contratação como piloto, cada companhia também aplica uma bateria de testes no momento de seleção, mantendo-se os pré-requisitos.

Essas exigências para exercer tais funções mostram um perfil de competência profissional que incluem além da escolarização obrigatória, conhecimentos técnicos, e habilidades no caso de pilotagem, sobretudo a capacidade física e psicológica. São exigências na seleção, verificados pela apresentação dos certificados de escolarização e da habilitação como piloto comercial, bem como por meio de exames e testes de conhecimentos gerais e específicos. O candidato deve apresentar determinados requisitos físicos estabelecidos, obter uma quantidade mínima de pontos nos exames de conhecimentos técnicos como também nos exames médicos, laboratoriais e psicológicos realizados nos hospitais da Aeronáutica.

Essas exigências não se limitam, no entanto, ao período de seleção e contratação. Foi verificado que há também procedimentos para controles periódicos do estado de saúde dos(as) trabalhadores(as) da aviação. Para isso, há uma avaliação periódica desses atributos, que podem ser discriminados nos itens abaixo, a saber:

1. Os que estão nos postos de piloto e controlador de tráfego aéreo são obrigados(as) a renovar a habilitação de saúde junto aos hospitais da Aeronáutica realizando exames de saúde, médicos e psicológicos;

2. Os que estão nos postos de piloto devem renovar semestralmente também sua habilitação técnica bem como no retorno das férias. São exames de conhecimentos como de habilidades técnicas de pilotagem. Os que estão nos postos de controlador de tráfego aéreo são encaminhados anualmente aos exames periódicos, e sempre no retorno das férias. Há também no retorno de férias ou licença um período de treinamento de retorno no próprio local de trabalho.

3. Os que não passam nos exames técnicos podem ser encaminhados a um programa de reciclagem ou novo treinamento;

4. A aprovação nos exames técnicos e o tempo de experiência não garantem aprovação nos exames de saúde. Um aspecto importante notado é que os que estão nos postos de piloto e forem reprovados(as) nos exames de saúde não podem renovar a carteira de habilitação de piloto e, por decorrência, ficam sem carteira e não podem exercer a função de piloto. Algumas empresas encaminham para um período de tratamento. Nesse período, são licenciados(as) e depois são novamente obrigados(as) a passar pelo check up. Mas há casos de demissão de piloto pelas empresas, uma vez que não apresentam a carteira de habilitação renovada.

No caso dos(as) que estão nos postos de controlador de tráfego aéreo, também não podem renovar a habilitação caso sejam reprovados(as) nos exames de saúde. Sem a habilitação necessária para o exercício da função, são obrigatoriamente afastados(as) 
das funções. Em se tratando de controladores da carreira militar ou civil do quadro do funcionalismo público, são encaminhados(as) para tratamento médico e tentar um novo exame. Podem também ser deslocados(as) para outras funções, normalmente administrativo-burocráticas.

Essa prática de gestão do trabalho não é nova. Nas Forças Armadas, o requisito condição física é o principal atributo exigido no recrutamento. Nesse caso, no processo de seleção, são buscados aqueles que são mais capazes fisicamente, dotados para suportar atividades pesadas e para enfrentar situações de guerra e conflitos. São escolhidos, assim, os que são considerados melhores para essas atividades, delineando um perfil de capacidade técnica, física e psicológica. Após a Segunda Guerra Mundial esse procedimento passa a ser também difundido na indústria. No caso da aviação civil, esses procedimentos são também adotados pela Aeronáutica para outras funções. Há a aplicação de testes físicos e psicotécnicos bem como as avaliações físicas e psicológicas, tanto para civis como para militares.

\section{Práticas de gestão e cuidados com a saúde}

A observação e os depoimentos puderam mostrar também alguns resultados dos quais podemos destacar as práticas de gestão nas relações de trabalho no que se refere a jornadas e salários e os ambientes de trabalho.

As relações de trabalho na aviação são, em geral, tensas. A responsabilidade é grande, e nem sempre possuem autoridade para decisão ou para alguma possibilidade de mudança, como no caso dos controladores.

1. A jornada de trabalho de pilotos é particular. São horas concentradas de trabalho durante três a quatro dias, em jornadas irregulares de trabalho e repouso, fora de casa e em fusos horários diferentes. Mas são contadas oficialmente somente as horas de voo realizadas por mês.

2. A jornada de controladores(as) de tráfego aéreo é de 6 e 8 horas diárias e em turnos rodiziantes, alternando picos e vales, diferenciados entre equipes do Rio de Janeiro e São Paulo e entre os servidores públicos e os contratados pela CLT;

3. Pilotos e controladores(as) são obrigados a assumir cada vez maiores responsabilidades. Um(a) controlador(a) de tráfego aéreo, por exemplo, controlava até 10 a 15 voos simultâneos, no final dos anos noventa do século XX. Isso chegou a até 30 voos em meados do ano 2000. O padrão internacional é de seis voos simultâneos por cada posto do controle de tráfego. E aumentou também a responsabilidade na medida em que cada voo pode representar até 300 passageiros.
4. O salário mensal para a função de controlador de tráfego era de $\mathrm{R} \$ 340,00$ mais gratificações de funções que podem chegar a R\$ 1.400,00 (valores do ano 2.000). São soldos estabelecidos para funções públicas da carreira militar e muitos consideram difícil alterar isso.

5. Há muita insatisfação em relação ao salário uma vez que, segundo os controladores, considerado muito abaixo da responsabilidade que assumem e do que é exigido. Para poder compensar essa remuneração baixa, muitos(as) recorrem a uma segunda atividade para complementar a renda, duplicando a jornada de trabalho para poder cuidar da manutenção da família.

6. A forma de pagamento de pilotos vem sendo alterada. Muitas empresas recorrem à prática de pagamento de um salário-base adicionado de uma parte variável conforme a quantidade de $\mathrm{km}$ voados, obrigando-os(as) a voarem mais horas, até mesmo contra a regulamentação da profissão.

Em relação a políticas e procedimentos rotineiros no cuidado da saúde do trabalhador, verificou-se que:

1. Não há acompanhamento das condições de trabalho;

2. Controladores(as) e pilotos não contam com um serviço de orientação e promoção da saúde nos locais de trabalho;

3. Os resultados dos exames de saúde não fazem parte de análise ou atenção por parte das chefias.

4. Foram identificados agravos na saúde de pilotos que trabalham em jornadas irregulares e vivendo precárias condições de repouso, mas não tem sido objeto de atenção.

5. Pilotos e controladores de tráfego aéreo, civis, são obrigados a renovar a habilitação de saúde, mas não possuem atendimento psicológico nem assistência médico-hospitalar que lhes possibilitem um tratamento ou acompanhamento contínuo.

6. Foram identificados entre controladores(as) de tráfego aéreo casos graves de doenças no trabalho, identificados como de "ordem psicológica", que motivaram afastamentos e mesmo morte por infarto do miocárdio. Mas os casos não são acompanhados para avaliação das causas.

7. Há indicações sobre os problemas com equipamentos e estudos sobre radiação decorrentes dos materiais eletro-eletrônicos. Mas não há programa de melhoria dessas condições dos locais pesquisados.

Verificou-se, ainda, que esses(as) trabalhadores(as) possuem muitas dificuldades para cuidar da saúde. Pri- 
meira, pelas condições de trabalho, dadas pelos locais de trabalho. A segunda dificuldade reside nas formas de gestão das jornadas de trabalho que dificultam repouso e alimentação em horários regulares. As jornadas de controladores de tráfego são em turnos rodiziantes e, no caso dos que possuem uma segunda atividade remunerada, são duplas jornadas de trabalho. E, no caso de mulheres nessas condições, a jornada chega a ser tripla. As jornadas de pilotos são irregulares, com horários de refeições, repousos e horários de sono completamente diferentes a cada dia e a cada semana. Ainda, somadas às relações tensas e estressantes da atividade, essas condições parecem contribuir fortemente para dificuldades em manter a acuidade e o sistema de controle em alerta.

Uma terceira dificuldade a destacar é responsabilidade que assumem para a promoção e manutenção da saúde. Muito embora seja uma exigência para o exercício dessas funções, os cuidados com a saúde ficam sob responsabilidade exclusiva do(a) trabalhador(a). $\mathrm{E}$ as dificuldades são tanto maiores quanto maior a faixa etária em que se encontra o trabalhador e as dificuldades financeiras que encontram para custear um programa de atendimento e acompanhamento junto às instituições de saúde.

Essas dificuldades são diferenciadas conforme o grupo de entrevistados. Dentre os(as) entrevistados(as), encontramos quatro formas diferenciadas. Um primeiro grupo de entrevistados(as) é o dos militares e os em regime CLT da Infraero, que são atendidos pelos hospitais da Aeronáutica. Estes contam com um atendimento, mas somente esse. Caso necessitem de especialista que não haja nesses hospitais, precisam recorrer a um serviço privado e pagar por isso.

Um segundo grupo é o dos que não contam com atendimento dos hospitais da Aeronáutica e pagam um plano de saúde. Nesse caso há um custo mensal do plano, mais as taxas adicionais em caso de exames médicos laboratoriais, conforme o plano e, no caso de atendimento hospitalar, há também taxas adicionais. No caso de um dos planos de saúde, por exemplo, a família paga entre $\mathrm{R} \$ 150,00$ a $\mathrm{R} \$ 450,00$ por mês. No primeiro caso, a mensalidade é menor, mas paga as taxas de serviços tanto de exames laboratoriais, $\mathrm{R} \$ 35,00$ por exame laboratorial, e no caso de atendimento hospitalar pode chegar a R\$ 3.500,00 em quarto coletivo/enfermaria (valores do ano 2000).

Um terceiro grupo é o dos que não contam com atendimento dos hospitais da Aeronáutica e como também não pagam nenhum plano de saúde, conseguem algum atendimento da rede pública quando precisam. Nesse grupo está a maioria dos controladores de tráfego. Há vários inconvenientes e dificuldades em verificar como a saúde está sendo cuidada. Além da restrita prática de buscar atendimento médico em situação preventiva, há as dificuldades de atendimento. Como os procedimentos, seja para marcação de consulta, cadastramento e exames, demandam sempre dispêndio de tempo, isso nem sempre pode ser realizado sem que haja dias de trabalho perdidos, o que pode significar que nem sempre são atendidos. Segundo os depoimentos, para obter esse atendimento se requer tempo e paciência, seja para as filas de espera para os diferentes procedimentos, e, com isso, muitos buscam atendimento somente em casos de emergência.

Um quarto grupo é o dos que não contam com atendimento dos hospitais da Aeronáutica nem com plano de saúde. E também não conseguem ser atendidos nos postos de atendimento da rede pública. Quando há emergência arriscam pagar serviço particular. Nesse grupo, há poucos. Para estes, a reclamação é que o salário nem sempre permite pagar até mesmo uma consulta do médico particular, que está em torno de $\mathrm{R} \$ 250,00$ (valores de 2.000).

Os desgastes, as perdas e as doenças aparecem nos organismos dos(as) pilotos e dos(as) controladores(as) de tráfego aéreo, e nos exames de saúde. A saúde do(a) trabalhador(a) não faz parte de um programa de cuidado e mesmo da avaliação da qualidade de vida no trabalho. As condições de realização de trabalho, os locais e salas de trabalho não são analisadas na mesma periodicidade em que são exigidos os exames médicos para renovação das habilitações dos(as) trabalhadores(as).

\section{Considerações Finais}

O estudo sobre as condições de trabalho na aviação é exemplar para mostrar como a saúde é gerenciada e como ela se desenvolve nas práticas de gestão. Trata-se de uma atividade em que não pode haver erro. Não há possibilidade de ler, ouvir errado ou adotar uma estratégia equivocada. E a decisão deve ser tomada com rapidez e operacionalizada, devendo ser comunicada, no caso do controle de tráfego, com clareza e rapidez, na velocidade em que funcionam os sistemas e equipamentos.

No caso da aviação civil brasileira, podemos ressaltar dois aspectos principais. Um primeiro aspecto é que a saúde é um atributo de qualificação, que pode ser analisado por dois requisitos. Há uma exigência explícita - que se constitui pela demanda de um conjunto dos exames físicos e laboratoriais no momento da contratação. Os(as) profissionais da aviação, ao serem contratados(as), devem atender a fortes exigências de qualificação, de um perfil de competência técnica e de boa saúde. Estes engajam sua capacidade, como competência profissional, suas aptidões físicas e sua energia, como parte implícita dos termos desse contrato. 
De outro lado, há uma exigência que é implícita - a de obrigatoriedade da manutenção permanente de boa saúde. Para manter-se na função e ou no emprego é preciso manter um conjunto de atributos implícitos de qualificação, compondo, nela, a de boa saúde como parte de sua capacidade. A falta de programas de promoção e acompanhamento da saúde desses trabalhadores mostra isso. Há pouca atenção com os efeitos nos organismos dos(as) pilotos e controladores(as) de tráfego aéreo.

Também as condições de trabalho ruins nem sempre são objeto de melhorias. Verifica-se que algumas condições de trabalho são vividas de modo perverso pelos(as) trabalhadores(as). A flexibilização dos horários e jornadas de trabalho é uma delas. Buscando aumentar a produtividade, as companhias aéreas impõem novas regras aos pilotos, pagando um saláriobase e uma cota variável de quantidade de $\mathrm{km}$ voados, flexibilizando horários e jornadas. Com isso, deixa ao piloto a responsabilidade pela quebra dessas regras convencionadas de trabalho na aviação. Por decorrência, é atribuído também sob a responsabilidade desses(as) profissionais os agravos que decorrem desse ato, como a fadiga, estresse, doenças profissionais e outros. Além disso, nem todos contam com atendimento médicohospitalar nas empresas ou dos hospitais específicos da Aeronáutica. Somente os militares podem contar com atendimento médico-hospitalar, mas tão e somente nos hospitais da Aeronáutica. Os demais precisam recorrer ao sistema privado ou plano de saúde pago pelo(a) próprio(a) trabalhador(a). A manutenção do emprego depende de como os profissionais conseguem cuidar de sua saúde e atender às exigências de controle periódico de saúde. No caso de pilotos de empresas privadas, estes(as) podem ser demitidos(as) quando não tiverem a habilitação aprovada.

Um segundo aspecto é que a saúde do trabalhador é considerada como um atributo natural e autônomo. A saúde é parte do atributo da capacidade do(a) trabalhador(a) juntamente com outras habilidades e competências técnicas profissionais. $\mathrm{O}$ (a) trabalhador(a) precisa apresentar sempre bom estado de saúde, atendendo às exigências para manter-se no emprego, que são controladas pela renovação obrigatória da habilitação periodicamente. Se não tiver um dos requisitos não pode renovar a habilitação e não pode exercer a função. Se a visão ou audição se torna deficiente, por exemplo, mesmo que por decorrência do exercício da atividade, essa deficiência torna o(a) trabalhador(a) incapaz ou incompetente para o exercício dessas funções. Assim, em realidade, para esses(as) trabalhadores(as) da aviação, ter boa saúde é condição básica de empregabilidade. As condições que os(as) trabalhadores(as) da aviação vivem em seu cotidiano de vida e de relações de trabalho mostram pontos conflituosos onde se situa a saúde. As empresas impõem exigências permanentes de capacidade do(a) trabalhador(a), física, mental e de conhecimentos e habilidades. Mas o corpo coletivo do(a) trabalhador(a) materializa as condições adversas sob as quais vive nessas relações sociais de trabalho. Essas práticas de gestão revelam também a noção de saúde tal como ela é compreendida nas relações cotidianas, estando no conteúdo de conflito das relações de trabalho. A saúde aparece, assim, como uma exigência. No entanto, ela aparece muito mais como um atributo implícito, como parte da capacidade de trabalho. A saúde é considerada, assim, como um atributo natural, estático, permanente e autônomo. E aplica-se o princípio da moral sanitária que considera os organismos como fenômenos autônomos e os agravos, perdas e doenças são debitados à responsabilidade individual de cada trabalhador.

\section{Nota}

* Agradecemos ao CNPq e FAPESP - Fundação de Amparo à Pesquisa do Estado de São Paulo - pelo apoio aos projetos de pesquisa. Durante o período entre 1997 e 1998, o estudo contou também com a equipe do Centro de Referência em Saúde do Trabalhador CEREST-SP: José Carlos do Carmo, Luiz Felipe Silva, Eda Muller, Paulo Sergio Silva e Rita de Cassia Araújo. Agradecemos ao Cecomsaer do CA pela autorização para realização do estudo e ao SRPV RJ e SP pela disponibilização do acesso aos locais de pesquisa, bem como aos responsáveis pelas salas e torres de controle e controladores de tráfego aéreo pela atenção dispensada. Agradecemos também aos responsáveis pelos dados do DAC e órgãos do então MA, ao Sindicato dos Aeronautas, Apvar, Ifalpa, Sinprovoo, ACTAG e ACTA. Agradecimentos especiais aos pilotos e controladores de tráfego aéreo pela atenção e disponibilidade.

\section{Referências Bibliográficas}

Barca, V. (1993). Mutations, réglementations, formes de concurrence et rapport salariales: le cas d'aviation. Tese de Doutorado, Université de Paris VII-Jussieu, Paris.

Berlinguer, G. (2005). Bioética cotidiana. Brasília: UNB.

Boltanski, L. (1984). Classes sociais e o corpo. Rio de Janeiro: Graal.

Castel, R. (1993). As metamorfoses da questão social. Petrópolis, RJ: Vozes.

Daniellou, F. (1985). Automatismes de processus et salles de controle. In B. Cassou et al. (Orgs.), Les risques du travail (pp. 45-52). Paris: La Découverte.

Dejours, C. (1985). Construire sa santé. In: B. Cassou et al. (Orgs.), Les risques du travail (18-21). Paris: La Découverte.

Dempsey, P. S. (1993). Flying Blind: The failure of Airline desregulation. Washington: Policy Economic Institute Report.

Déoux, S. et al. (1993). L'écologie c'est la santé. Paris: FrisonRoche; 1993.

Duraffourg, J. (1985). La relation santé-travail: une question complexe. In: B.Cassou et al. (Orgs.), Les risques du travail (22-27). Paris: La Découverte. 
Fassin, D. (1996). L'espace politique de la santé. Paris: PUF.

Ferreira, L. L. (1992). Voando com os pilotos. São Paulo: Apvar.

Fischer, F. M. (1991). Jornadas de trabalho em horários irregulares. Contato, 161(24), 21-34.

Gille, B. (1978). Histoire des techniques. Technique et civilizations. Technique et sciences. Paris: Gallimard.

Gras, A. (1985). Le pilote, le contrôleur et l'automate. Paris: Iris.

Itani, A. (2000). Condições de trabalho de controladores de tráfego aéreo. Relatório de pesquisa. São Paulo: Fapesp/ UNESP.

Itani, A. (2004). Condições de trabalho e riscos de controladores de tráfego aéreo. Relatório de pesquisa, segunda parte. São Paulo: Unesp/Fapesp.

Lavorel, L. (1987). La qualification du personnel navigant technique de l'aéronautique civil em France. Formation-emploi, 17, 17-37.

Vidal, M. \& Moreira, S. (1999). Relatórios de pesquisas ergonômicas. Rio de Janeiro: Fundação Coppetec/Gente Coppe/ UFRJ.

Alice Itani é mestre em Psicologia Social pela PUC-SP, doutora em Sociologia pela EHESS, Livre docente pela UNESP. Foi professora da UNESP. Atualmente também professora do Mestrado em Gestão Integrada em Saúde do Trabalho e Meio Ambiente do Senac.

Endereço para correspondência: Centro Universitário

Senac - Campus Santo Amaro Av. Engenheiro Eusébio Stevaux, 823. 04696-000 - São Paulo.

Email: aitani@terra.com.br

\section{Saúde e gestão na aviação: a experiência de pilotos e} controladores de tráfego aéreo

Alice Itani

Recebido: $25 / 01 / 2008$

$1^{\text {a }}$ revisão: $28 / 10 / 2008$

$2^{a}$ revisão: $30 / 03 / 2009$

Aceite final: 17/04/2009 